\title{
PREVALÊNCIA DA ANEMIA FERROPRIVA NO BRASIL: ANÁLISE QUANTITATIVA EM POPULAÇÃO PEDIÁTRICA
}

\author{
Bianca Santos Pedrosa*1, Jamilly Gusmão Coelho² ${ }^{2}$, Mariane Costa Santos de Tavares ${ }^{3}$, Adrianne \\ Rocha Luz ${ }^{4}$, Ana Carolina Meira Trindade4, Guilherme Massanori Nagao ${ }^{4}$, Larissa Hora \\ Moreira4 ${ }^{4}$ Marco Antonio Fernandes de Sousa Lima ${ }^{4}$, Thays Benevides Ventura Esteves ${ }^{4}$, Paolla \\ Gabrielly Brito Cúrcio ${ }^{5}$ and Victória Eça de Britto $^{6}$
}

${ }^{1}$ Autor Correspondente, Discente do Curso de Graduação de Medicina. Faculdade Santo Agostinho - FASA, Vitória da Conquista-Bahia. ${ }^{2}$ Docente do Curso de Graduação de Medicina. Faculdade Santo Agostinho - FASA,

Vitória da Conquista-Bahia. ${ }^{3}$ Fisioterapeuta. Pós-graduada em Terapia Intensiva. Discente do Curso de Graduação de Medicina. Faculdade Santo Agostinho - FASA, Vitória da Conquista - Bahia. ${ }^{4}$ Discente do Curso de Graduação de Medicina. Faculdade Santo Agostinho - FASA, Vitória da Conquista-Bahia. ${ }^{5}$ Discente do Curso de Graduação de Medicina. Universidade Estadual da Bahia - UESB, Vitória da Conquista-Bahia. ${ }^{6}$ Discente do Curso de Graduação de Medicina. Faculdade de Tecnologia e Ciência - FTC, Salvador - Bahia.

\section{ARTICLE INFO}

Article History:

Received $27^{\text {th }}$ January, 2021

Received in revised form

$08^{\text {th }}$ February, 2021

Accepted $02^{\text {nd }}$ March, 2021

Published online $13^{\text {th }}$ April, 2021

Key Words:

Deficiência de Ferro

Anemia Ferropriva

Pediatria.

*Corresponding author:

Bianca Santos Pedrosa

\begin{abstract}
Objetivo: Analisar os dados registrados no Sistema de Informações Hospitalares (SIH/SUS), os quais são fornecidos pelo Departamento de Informática do SUS (DATASUS), da prevalência de anemia ferropriva em crianças, nas cinco regiões do Brasil, entre os anos de 2010 e 2020. Métodos: Pesquisa descritiva, do tipo quantitativa, por meio da coleta de dados do Sistema de Informações Hospitalares (SIH/SUS), os quais são fornecidos pelo Departamento de Informática do SUS (DATASUS), referentes aos anos de 2010 a 2020, incluindo pacientes na faixa etária menor de 1 ano, de 1 a 4 e de 5 a 9 anos, em caráter de atendimento eletivo ou de urgência, de regime público ou privado. Os dados coletados foram transportados para uma planilha do programa Microsoft Office Excel 2010, onde todas as variáveis foram tabuladas e apresentadas como dados absolutos e, posteriormente, calculou-se as porcentagens utilizando o mesmo programa. As análises estatísticas foram realizadas através da média e do desvio percentual. Resultados: O maior registro no número de internações foi no ano de 2015 , e os menores, nos anos de 2010 e 2020. A região Nordeste prevaleceu sob as demais, enquanto a região CentroOeste apresentou os menores registros. Quanto a faixa etária, as internações por anemia ferropriva foram predominantes em crianças menores de 1 ano.Consideraçõesfinais: A prevalência da anemia ferropriva na população pediátrica permanece alta no Brasil. Tal cenário é reflexo da baixa adesão as medidas profiláticas de combate a anemia, além das precárias condições socioeconômicas e alimentares em determinadas regiões brasileiras, fato esse que, quando associado a alta demanda nutricional para o desenvolvimento e o crescimento adequado das crianças, aumenta a prevalência da doença no país.
\end{abstract}

Copyright $($ C 2021, Bianca Santos Pedrosa. This is an open access article distributed under the Creative Commons Attribution License, which permits unrestricted use, distribution, and reproduction in any medium, provided the original work is properly cited.

Citation: Bianca Santos Pedrosa, Jamilly Gusmão Coelho, Mariane Costa Santos de Tavares, Adrianne Rocha Luz et al. "Prevalência da Anemia Ferropriva no Brasil: Análise quantitativa em população Pediátrica”, International Journal of Development Research, 11, (04), $45881-45888$.

\section{INTRODUCTION}

Aanemia ferropriva é uma entidade clínica de origem multifatorial, sendo sua principal causa a deficiência de ferro, que é considerada a carência nutricional mais comum em crianças, estando associada a mais de $60 \%$ dos casos em todo o mundo (KASSEBAUM, et al, 2014). Essa condição é considerada um grave problema de saúde pública no Brasil em virtude da estreita relação com o desenvolvimento infantil e das altas prevalências em todos os segmentos, acometendo principalmente crianças menores de três anos de idade, atingindo prioritariamente as camadas menos favorecidas, 
de menor renda e desenvolvimento (PAZIRANDEH, et al, 2020). Segundo a Organização Mundial da Saúde (OMS), anemia é definida como a condição na qual a concentração sanguínea de hemoglobina se encontra abaixo dos valores esperados (inferior a 2 desvios padrão), tornando-se insuficiente para atender as necessidades fisiológicas exigidas de acordo com idade, sexo e altitude. Fatores de risco que frequentemente levam a anemia ferropriva incluem a ingestão insuficiente de ferro de boa biodisponibilidade, a introdução de leite de vaca antes dos 12 meses de idade, a presença dedoenças que afetam a absorção gastrointestinal do mineral - colite induzida por proteína do leite de vaca, giardíase, doença de Chron e doença Celíaca(HILL, LI, HOPPIN, 2020), além de condições no período perinatal (compreendido entre a $28^{\mathrm{a}}$ semana de gestação ao $7^{\circ}$ dia de vida do recém-nascido) que prejudiquem o estoque de ferro, a exemplo da prematuridade, da hemorragia fetal-materna e da ingestão alimentar insuficiente durante a primeira infância(COLLARD, 2009). Essa morbidade, quando não diagnosticada e tratada de maneira eficaz, traz repercussões clínicas danosas e importantes no desenvolvimento de habilidades cognitivas, comportamentais, linguagem e capacidades motoras das crianças, sendo que o possível impacto negativo permanece mesmo após o tratamento precoce por décadas, especialmente em crianças poucos estimuladas ou de baixo nível socioeconômico (LOBERA, 2014).

Há evidências crescentes de que a anemia por deficiência de ferro em crianças pequenas pode levar a atrasos no desenvolvimento, que parecem ser irreversíveis. Estudos de corte longitudinal na América Central e do Sul demonstraram que essas alterações persistem, pelo menos parcialmente, mesmo se for dada terapia com ferro suficiente para corrigir a anemia. Há um comprometimento neurocognitivo que inclui um processamento visual e auditivo mais lento, além de um comprometimento da linguagem e das capacidades motoras das crianças (PARKIN, et al, 2020).A carência de ferro também pode produzir alterações na imunidade não específica, visto que parece estar associada a defeitos leves a moderados na função de leucócitos e linfócitos, incluindo produção defeituosa de IL-2 e IL-6, condição que se associa à diminuição da capacidade de exercício, em parte porque o ferro é um cofator essencial para o metabolismo aeróbio acionado por enzimas (THIBAULT,1993).A deficiência de ferro predispõe ainda a cáries dentárias e menor discriminação de odores em comparação aos grupos controle, com associação a quadros de Pica (desejo intenso de itens não alimentares como giz, sabão, argila, rochas, papelão, arroz cru, papel) e Pagofagia (desejo por gelo), sendo que esse último é particularmente comum e específica para o estado de deficiência de ferro (SOCIEDADE BRASILEIRA DE PEDIATRIA, 2018).Ademais, a anemia ferropriva tem sido associada à trombose de veias cerebrais. Em um grande estudo caso-controle no Canadá, crianças previamente saudáveis com AVC tinham 10 vezes mais chances de ter anemia por deficiência de ferro do que crianças saudáveis sem AVC. Os mecanismos para essa complicação não são completamente claros, mas podem estar relacionados à trombocitose ou como resultado de propriedades reológicas anormais em crianças com anemia por deficiência de ferro grave (BENEDICT, et al, 2004). Ao associar a relevância do problema às dificuldades na obtenção de um diagnóstico precoce, com exames simples e objetivos, tornou-se necessária a criação de diferentes intervenções profiláticas e educativas de cunho governamental e não governamental, a fim de interferir nos níveis de anemia ferropriva na população. Uma das ações mais importantes instituídas no Brasil com este fim foi o desenvolvimento da suplementação profilática com sulfato ferroso desde 2005 - Programa Nacional de Suplementação de Ferro (PNSF) para todas as crianças de 6 a 24 meses de idade - na dosagem de $1 \mathrm{mg} / \mathrm{kg}$ peso/dia, gestantes ao iniciarem o pré-natal, independentemente da idade gestacional até o terceiro mês pós-parto, e na suplementação de gestantes com ácido fólico, sendo que esses suplementos são gratuitamente disponíveis nas farmácias das Unidades Básicas de Saúde, em todos os municípios brasileiros(MINISTÉRIO DA SAÚDE, 2013).A recomendação vigente atualizada da Sociedade Brasileira de Pediatria orienta a suplementação profilática com dose de $1 \mathrm{mg}$ de ferro elementar $/ \mathrm{kg}$ ao dia dos 3 aos 24 meses de idade, independentemente do regime de aleitamento.
Para lactentes nascidos pré-termo ou com baixo peso (menor de $1500 \mathrm{~g}$ ), a recomendação é de suplementação com $2 \mathrm{mg} / \mathrm{kg} /$ dia a partir do $30^{\circ}$ dia até os 12 meses. Já para os prematuros com baixo peso (entre $1000 \mathrm{~g}$ e $1500 \mathrm{~g}$ ) a recomendação de suplementação é de $3 \mathrm{mg} / \mathrm{kg} /$ dia até os 12 meses; e para recém-nascidos com menos de $1000 \mathrm{~g}$, de $4 \mathrm{mg} / \mathrm{kg} / \mathrm{dia}$. Após o $1^{\circ}$ ano de vida, a suplementação em todos os casos reduz-se para a dose de $1 \mathrm{mg} / \mathrm{kg} /$ dia por mais 12 meses (SOCIEDADE BRASILEIRA DE PEDIATRIA, 2018).Apesar da eficácia, a adesão profilática do sulfato ferroso é geralmente baixa devido sua palatabilidade e pelo surgimento de efeitos colaterais em função do uso prolongado (POWERS, et al, 2020). Além disso, outras medidas, como a fortificação de farinhas de trigo e milho com ferro e ácido fólico (Resolução RDC n 150, de 13 de Abril de 2017 da Agência Nacional de Vigilância Sanitária - ANVISA); asAções de Educação Alimentar e Nutricional - EAN (Decreto N $\mathrm{N}^{\circ}$ 7.272, de 25 de agosto, de 2010) que estimulam o acesso universal à alimentação adequada e ao aleitamento materno exclusivo e prolongado; e a Estratégia NutriSUS,criada pelo Ministério da Saúde em 2014, que consiste na adição de sachês contendo 15 micronutrientes em pó na alimentação de crianças de seis meses a 3 anos e 11 meses matriculadas em creches participantes do Programa Saúde na Escola (PSE), também são estratégias que visam a prevenção da anemia ferropriva em crianças (MINISTÉRIO DA SAÚDE, 2015). Considerando esse cenário e a relevância do problema, o presente estudo procura descrever e analisar a prevalência da anemia ferropriva em crianças no Brasil no período compreendido entre 2010 e 2020, relacionando tais dados com as políticas vigentes à época para combate a anemia, a fim de estimular e embasar novas pesquisas sobre o tema, contribuindo assim para um melhor planejamento das ações em saúde e uma assistência coletiva mais eficiente e de menor custo.

\section{MATERIAIS E MÉTODOS}

A presente pesquisa é classificada comoquantitativa descritiva, pois o estudo traduz em números informações (GIL, 2010) referentesao objetivo primordial desta, que é a descrição da prevalência de anemia ferropriva na população pediátrica no período de 2010 a 2020 , de modo a avaliar as flutuações do número de casos frente às políticas públicas vigentes à época para combate à anemia. Os dados utilizados foram coletados do Sistema de Informações Hospitalares (SIH/SUS), os quais são fornecidos pelo Departamento de Informática do SUS (DATASUS). Os dados coletados do SIH/SUS foram transportados para uma planilha do programa Microsoft Office Excel 2010, em que as colunas representavam o período delimitado na pesquisa (2010 a 2020) e as linhas representam as variáveis a serem analisadas. As variáveis, todas do tipo quantitativas, foram tabuladas e apresentadas como dados absolutos e, posteriormente, quando necessário, calculouse as porcentagens utilizando o mesmo programa. As análises estatísticas foram realizadas através da média e do desvio percentual. Foram inclusos pacientes com as seguintes faixas etárias: menor de 1 ano, de 1 a 4 e de 5 a 9 anos, em caráter de atendimento eletivo ou de urgência, de regime público ou privado, no período compreendido entre 2010 e 2020. Quanto aos critérios de exclusão, foram desconsiderados os pacientes com idade acima de 9 anos pois, segundo a OMS, a adolescência compreende o período de vida entre 10 e 20 anos incompletos, sendo assim, dados de indivíduos que fazem parte dessa categoria etária não se encaixam na presente pesquisa. Dispensou-se a submissão ao Comitê de Ética e Pesquisa, pois os dados agregados e informações utilizados são fornecidas pelo DATASUS, portanto, de domínio público, cujos todos os direitos e sigilo estão prontamente assegurados pelo Sistema de Informações Hospitalares do Sistema Único de Saúde (SIH-SUS).A pesquisa foi conduzida observando a Resolução 466/12 CONEP-CNS/MS.

\section{RESULTADOS}

Como demonstrado na Tabela 1, no período estudado, que se estende de 2010 a 2020, o número de internações decorrentes de anemia ferropriva em crianças menores de 1 ano,de 1 a 4 e de 5 a 9 anos, nas 
Tabela 1. Número de internações por anemia ferropriva de acordo as cinco regiões do Brasil, considerando crianças menores de 1 ano, de 1 a 4 anos e de 5 a 9 anos. Fonte:SIH/SUS.

\begin{tabular}{lllllll}
\hline Ano & Região Norte & Região Nordeste & Região Sudeste & Região Sul & Região Centro-Oeste & Total \\
\hline 2010 & $5.548,24$ & $25.749,67$ & $13.323,15$ & $6.986,04$ & $3.089,52$ & $54.696,62$ \\
2011 & $30.753,25$ & $139.627,31$ & $110.542,58$ & $33.339,57$ & $22.181,43$ & $336.444,14$ \\
2012 & $33.467,25$ & $129.353,39$ & $106.054,88$ & $41.872,13$ & $15.431,69$ & $326.179,34$ \\
2013 & $20.077,86$ & $160.368,43$ & $62.102,49$ & $26.822,74$ & $25.038,16$ & $294.409,68$ \\
2014 & $33.628,62$ & $93.153,52$ & $94.755,71$ & $59.278,86$ & $22.749,09$ & $303.565,80$ \\
2015 & $34.316,42$ & $185.801,59$ & $125.703,30$ & $54.884,01$ & $12.166,81$ & $412.872,13$ \\
2016 & $22.599,36$ & $121.727,75$ & $99.404,65$ & $94.559,73$ & $17.256,87$ & $355.548,36$ \\
2017 & $22.693,21$ & $97.773,88$ & $113.455,43$ & $69.674,41$ & $23.196,64$ & $326.793,57$ \\
2018 & $32.578,20$ & $125.929,61$ & $98.161,14$ & $60.673,78$ & $18.605,80$ & $33.948,53$ \\
2019 & $39.380,58$ & $146.697,14$ & $131.189,59$ & $41.432,11$ & $18.169,44$ & $376.868,86$ \\
2020 & $35.753,95$ & $73.964,00$ & $76.995,49$ & $30.477,46$ & $32.231,67$ & $249.422,57$ \\
Total & $310.796,94$ & $1.300 .146,29$ & $1.031 .688,41$ & $520.000,84$ & $210.117,12$ & $3.372 .749,60$ \\
\hline
\end{tabular}

Tabela 2. Número de internações por anemia ferropriva de acordo as cinco regiões do Brasil, considerando crianças menores de 1 ano. Fonte:SIH/SUS

\begin{tabular}{llcccc}
\hline Ano & Região Norte & Região Nordeste & Região Sudeste & Região Sul & Região Centro-Oeste \\
\hline 2010 & 515,70 & $7.459,92$ & $5.760,56$ & $1.816,44$ & $2.331,97$ \\
2011 & $7.106,43$ & $54.518,75$ & $49.138,77$ & $14.088,67$ & $7.068,38$ \\
2012 & $13.583,22$ & $49.362,26$ & $57.022,54$ & $15.188,88$ & $6.068,82$ \\
2013 & $3.922,98$ & $99.258,96$ & $22.423,08$ & $9.829,66$ & $17.924,99$ \\
2014 & $6.626,70$ & $37.086,62$ & $51.054,70$ & $42.843,49$ & $11.525,39$ \\
2015 & $12.412,72$ & $76.783,56$ & $72.142,19$ & $18.363,92$ & $4.001,97$ \\
Total & $44.167,75$ & $324.470,07$ & $257.541,84$ & $102.131,06$ & $48.921,52$ \\
\hline
\end{tabular}

Tabela 3. Número de internações por anemia ferropriva de acordo as cinco regiões do Brasil, considerando crianças de 1 a 4 anos. Fonte:SIH/SUS

\begin{tabular}{|c|c|c|c|c|c|c|}
\hline Ano & Região Norte & Região Nordeste & Região Sudeste & Região Sul & Região Centro-Oeste & Total \\
\hline 2010 & $2.133,92$ & $13.942,23$ & $5.026,72$ & $4.023,03$ & 757,55 & $25.883,45$ \\
\hline 2011 & $16.500,44$ & $54.180,01$ & $44.614,00$ & $17.822,37$ & $10.939,44$ & $144.056,26$ \\
\hline 2012 & $12.949,30$ & $48.306,03$ & $34.766,36$ & $22.329,24$ & $8.021,85$ & $126.372,78$ \\
\hline 2013 & $8.486,19$ & $35.952,69$ & $32.429,92$ & $14.980,80$ & $5.862,75$ & $97.712,35$ \\
\hline 2014 & $16.627,70$ & $40.073,16$ & $34.673,97$ & $13.229,48$ & $7.360,06$ & $111.964,37$ \\
\hline 2015 & $11.667,92$ & $33.806,40$ & $30.724,82$ & $10.074,44$ & $4.087,79$ & $90.361,37$ \\
\hline Total & $68.365,47$ & $226.260,52$ & $182.235,79$ & $82.459,36$ & $37.029,44$ & $596.350,58$ \\
\hline
\end{tabular}

Tabela 4. Número de internações por anemia ferropriva de acordo as cinco regiões do Brasil, considerando crianças de 5 a 9 anos. No ano de 2010, para a região Centro-Oeste, não havia números registrados. Fonte:SIH/SUS.

\begin{tabular}{llcccc}
\hline Ano & Região Norte & Região Nordeste & Região Sudeste & Região Sul & Região Centro-Oeste \\
\hline 2010 & $2.898,62$ & $4.347,52$ & $2.535,87$ & $1.146,57$ & - \\
2011 & $7.146,38$ & $30.928,55$ & $16.789,81$ & $1.428,53$ & $4.173,61$ \\
2012 & $6.934,73$ & $31.685,10$ & $14.265,98$ & $4.354,01$ & $1.341,02$ \\
2013 & $7.668,69$ & $25.156,78$ & $7.249,49$ & $2.012,28$ & $1.250,42$ \\
2014 & $10.374,22$ & $15.993,74$ & $9.027,04$ & $3.205,89$ & $3.863,64$ \\
2015 & $3.620,19$ & $12.729,39$ & $6.374,26$ & $1.825,21$ & $1.303,02$ \\
Total & $38.642,83$ & $120.841,06$ & $56.242,45$ & $13.972,49$ & $46.58,88$ \\
\end{tabular}

NÚMERO DE CASOS POR ANO

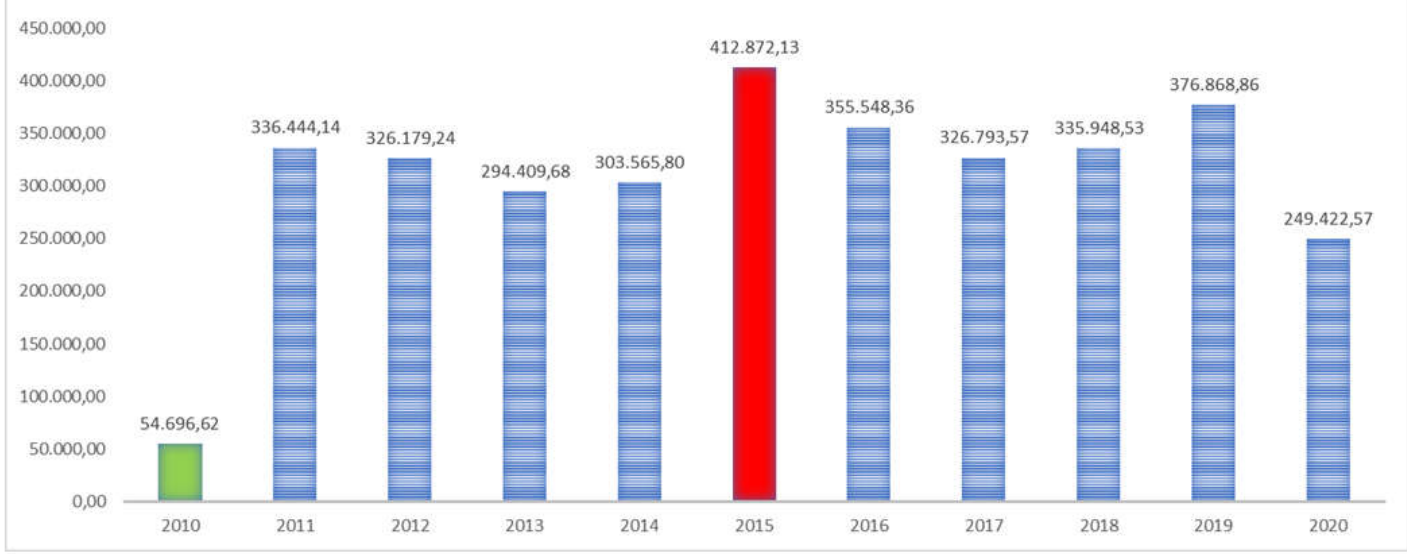

Figura 1. Demonstração gráfica do número de internações por anemia ferropriva de acordo as cinco regiões do Brasil, considerando crianças menores de 1 ano, de 1 a 4 anos e de 5 a 9 anos. Fonte:Bianca Santos Pedrosa (2021). 
cinco regiões do Brasil, foi de 3.372.749,60, sendo observado flutuações até o ano de 2020. O maior registro no número de internações foi no ano de 2015 (Figura 1), com um número até sete vezes maior de internações em comparação ao primeiro ano analisado. O menor registro ocorreu no ano de 2010 (Figura 1), que correspondeu à apenas 2\% (54.696,62 internações) do total de internações. Além disso, verificou-se uma diminuição significativa no número de internações em 2020, que apresentou uma redução percentual de $34 \%$ em relação ao ano anterior. Em relação as regiões brasileiras, observa-se que a região Nordeste tende a prevalecer sob as demais, correspondendo a 38,5\% (1.300.146,29 internações) do número total de internações registradas (Figura 2). Exceção a isto foram os anos de 2014, 2017 e 2020 (Figuras 2E, 2H e 2K), quando o Sudeste apresentou os maiores números. Em contrapartida, a região Centro-Oeste, seguida da Norte e da Sul, apresentou-se com o menor número de internações, correspondendo, respectivamente, a apenas $6,2 \%(210.117,12$ internações $)$ do número total de casos no período de 2010 a 2020 . No que se refere a faixa etária, notou-se que, no período de 2010 a 2015 , as internações por anemia ferropriva foram predominantes na faixa etária de crianças menores de 1 ano (Figura $3)$. Do total de internações registradas nesse período de 5 anos (1.674.461,23 internações), 47\% correspondem a crianças menores de 1 ano, $35,6 \%$ às que possuem entre 1 e 4 anos, e apenas $17,4 \%$ foram atribuídas àquelas entre 4 e 9 anos de idade (valores absolutos podem ser vistos nas Tabelas 2, 3 e 4). No ano de 2011, no entanto, o grupo etário entre 1 e 4 anos apresentou um aumento considerável em relação aos demais, com um aumento percentual de 20,8\% $(24.786,144)$ em relação a sua média $(119.270,16)$ no período considerado. Os demais anos, de 2015 a 2020, não foram analisados quanto à faixa etária por ausência de dados registrados no SIH/SUS.

\section{DISCUSSÃO}

Os números de internações por anemia ferropriva na população pediátrica brasileira sofreram flutuações ao longo do período estudado. Os maiores valoresforamda região Nordeste, dado esse que entra em consonância com o resultado de vários outros estudos, a exemplo de uma revisão sistemática de 53 artigos brasileiros realizada em 2009 pelo grupo de Jordão, com um total aproximado de 21000 crianças avaliadas, onde a prevalência descrita para anemia foi de $53 \%$, sendo maior na região Nordeste (JORDÃO, BERNARDI, FILHO, 2009). Tal fato ocorre, provavelmente, pela presença de vários fatores de risco para anemia nessa região, como o baixo consumo de ferro heme devido às condições de pobreza, a alta prevalência de desnutrição energético-proteica - incluindo as formas graves de marasmo, além das condições ambientais desfavoráveis para o plantio de frutas e verduras. Uma pesquisa (OSORIO, et al, 2001) com desenho de estudo semelhante a este, mas com diferenças relativas à população da metodologia e ao período delimitado, avaliou 777 crianças de seis a 59 meses nas áreas metropolitana, urbana (interior) e rural nordestinas e encontrou $40,9 \%$ de anemia. Dentre elas, a zona rural apresentou maior prevalência $(51,4 \%)$ de anemia do que as regiões urbana $(35,9 \%)$ e metropolitana $(39,6 \%)$, demonstrando, mais uma vez, a relação intrínseca da doença com as condições alimentares e ambientais, visto que, na zona rural, devido ao saneamento básico precário, há alto risco de parasitoses, com consequente perda de sangue por doença gastrointestinal, favorecendo a anemia ferropriva. Nos anos em que o Nordeste não liderou - 2014, 2017 e 2020, o Sudeste apresentou o maior número de internações. Levanta-se duas hipóteses para explicar tal fato: a primeira é que, por ser a região mais desenvolvida do país, os casos não ficaram subnotificados, o que aumentou o número de diagnósticos registrados em relação às demais regiões brasileiras; e a segunda é que, apesar da Região Sudeste ser a mais rica do país, supõe-se que com a maior inserção das mães no mercado de trabalho e com o término da licença-maternidade, a criança fique aos cuidados de pessoas menos qualificadas para seu trato alimentar, levando-as a consumir alimentos de alto valor calórico mas com baixo valor nutricional - a exemplo dos industrializados, o que favorece o aumento da prevalência de anemia.
Os altos casos de internações registrados no Nordeste e no Sudeste brasileiros evidenciou, mais uma vez, o que foi demonstrado pela Pesquisa Nacional de Demografia e Saúde - PNDS realizada em 2006, onde foi avaliado, pela primeira vez em nível nacional, a prevalência de anemia em crianças. Nela, observou-se que $20,9 \%$ das menores de 5 anos apresentavam anemia, ou seja, aproximadamente 3 milhões de crianças brasileiras. As maiores prevalências foram observadas no Nordeste $(25,5 \%)$, Sudeste $(22,6 \%)$ e Sul $(21,5 \%)$. A região Norte $(10,4 \%)$ e a região Centro-Oeste $(11,0 \%)$, por sua vez, apresentaram as prevalências mais baixas. A presente pesquisa demonstrou a região Centro-Oeste com o menor número de internações, o que entra em consonância com outras pesquisas, a exemplo da supracitada. Levanta-se duas hipóteses para explicar isso: a primeira é o fato de a região Centro-Oeste possuir as menores densidades demográficas do Brasil (8,7 habitantes por quilômetro quadrado), abrigando, segundo valores de 2019 do Instituto Brasileiro de Geografia e Estatística (IBGE), 16.297.074 habitantes, e, portanto, um menor número de indivíduos doentes; a segunda hipótese tem relação com uma característica marcante do Centro-Oeste, que é sua força no setor primário da economia. As atividades agrícolas e pecuaristas são destaques nos três maiores estados em extensão territorial, com ênfase para o Mato Grosso, que possui o maior rebanho bovino brasileiro; logo, supõe-se que as crianças da região têm mais acesso a carnes, uma fonte alimentar heme que possui uma alta biodisponibilidade de ferro, prevenindo então a anemia ferropriva.

A região Norte e a região Sul procederam a Centro-Oeste com os menores números de internações. Na região Norte, isso pode ser explicado pela baixa concentração de profissionais de saúde na região, o que, possivelmente, gera redução do acesso à saúde com consequente subnotificação dos casos de anemia ferropriva. Um estudo feito em 2016 que avaliou os padrões de desigualdades regionais na saúde, usando também a plataforma DATASUS, incluiu a região Norte no chamado "Grupo 2", que se caracteriza por apresentar níveis médios e altos de desenvolvimento socioeconômico e baixa oferta e complexidade dos serviços de saúde locais; nesse mesmo estudo, foi demonstrado que o Norte teve seu desenvolvimento socioeconômico muito atrelado à expansão da agropecuária e mineração, com vocação exportadora, uso intenso de tecnologia e ampliação da infraestrutura logística (transporte e comunicação). Tais atividades resultaram num crescimento populacional concentrado em poucos centros urbanos, nem sempre seguido de investimentos e planejamento capazes de absorver as novas demandas por serviços urbanos e sociais, o que inclui os serviços de saúde (ALBUQUERQUE, et al, 2017). A região Sul acompanha essa tendência de menor número de internações, possivelmente por uma boa qualidade de vida na região, a criação de gado bovino para consumo local e para abastecer o mercado interno, além do fácil acesso à saúde pela população. Considerando o número de profissionais por mil habitantes, a Região Sul apresenta melhores indicadores em relação ao país (KROTH, GEREMIA, F., GEREMIA D.S., 2020). Na comparação internacional, a média desse indicador para o profissional médico nos países da OCDE situa-se em $3,4 \mathrm{em}$ 2018, isto é, bem acima das médias regional e nacional (OCDE, 2019).

No que diz respeito a prevalência no período estudado, o ano de 2015 apresentou o maior número de internações infantil por anemia ferropriva. Uma hipótese para explicar tal fato seria a baixa adesão profilática do sulfato ferroso graças a combinação de diversos fatores: gosto desagradável, escurecimento dos dentes e fezes e sintomas gastrointestinais em função do uso prolongado (MINISTÉRIO DA SAÚDE, 2015); aliado a essa limitação na adesão, supõe-se ainda que a estratégia NutriSUS, implementada em 2014, ainda não estava sendo aplicada de forma correta. Esse uso inadequado dos sachês contendo micronutrientes em pó pode estar relacionado com o esquema de administração errôneo ou ainda com uma das principais dificuldades observadas nessa estratégia: a importância que os pais desenvolvem nesse contexto, pois eles deveriam conceder a autorização para que as crianças recebessem a fortificação (FARIAS, 2016). 

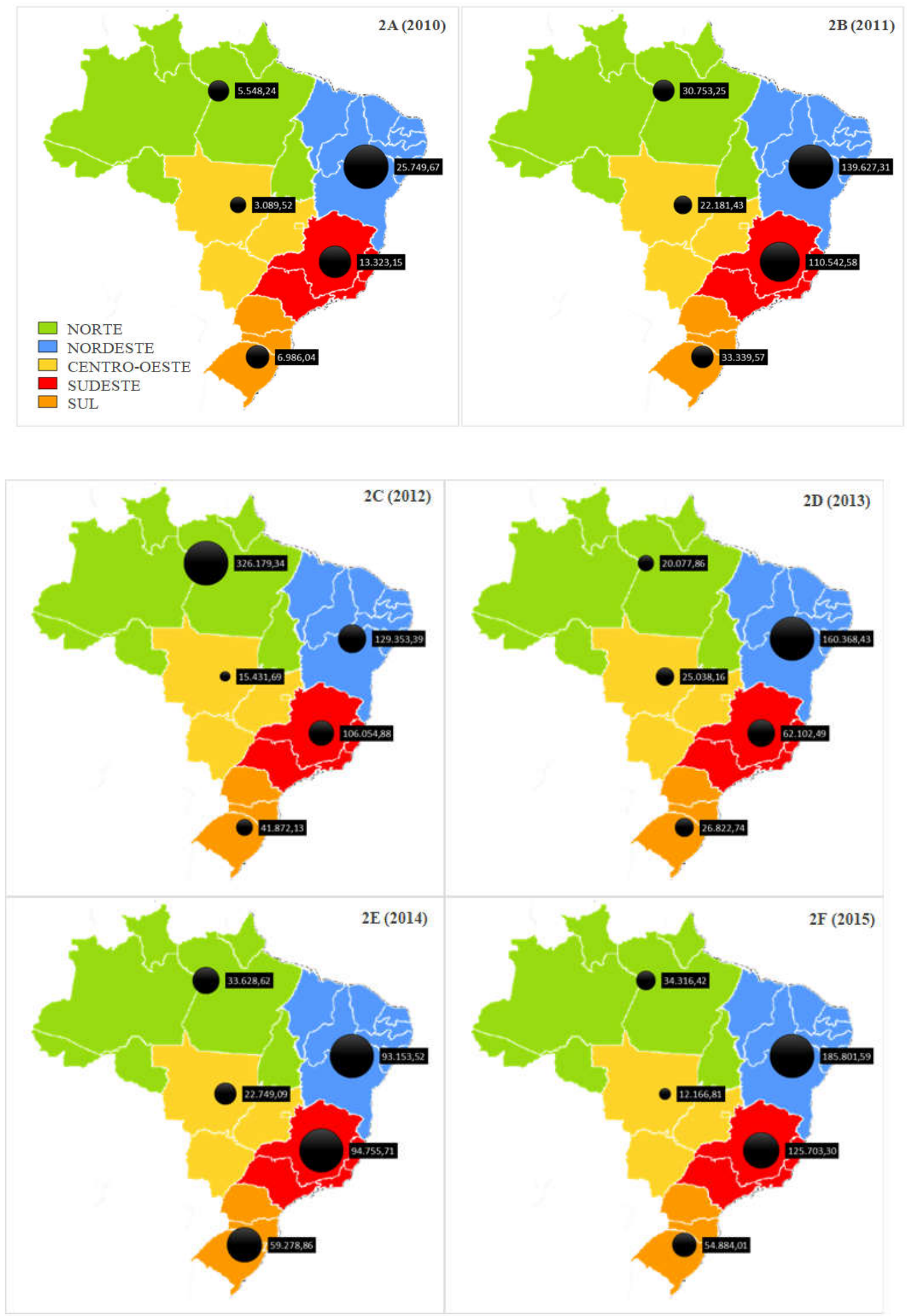

Continue ... 

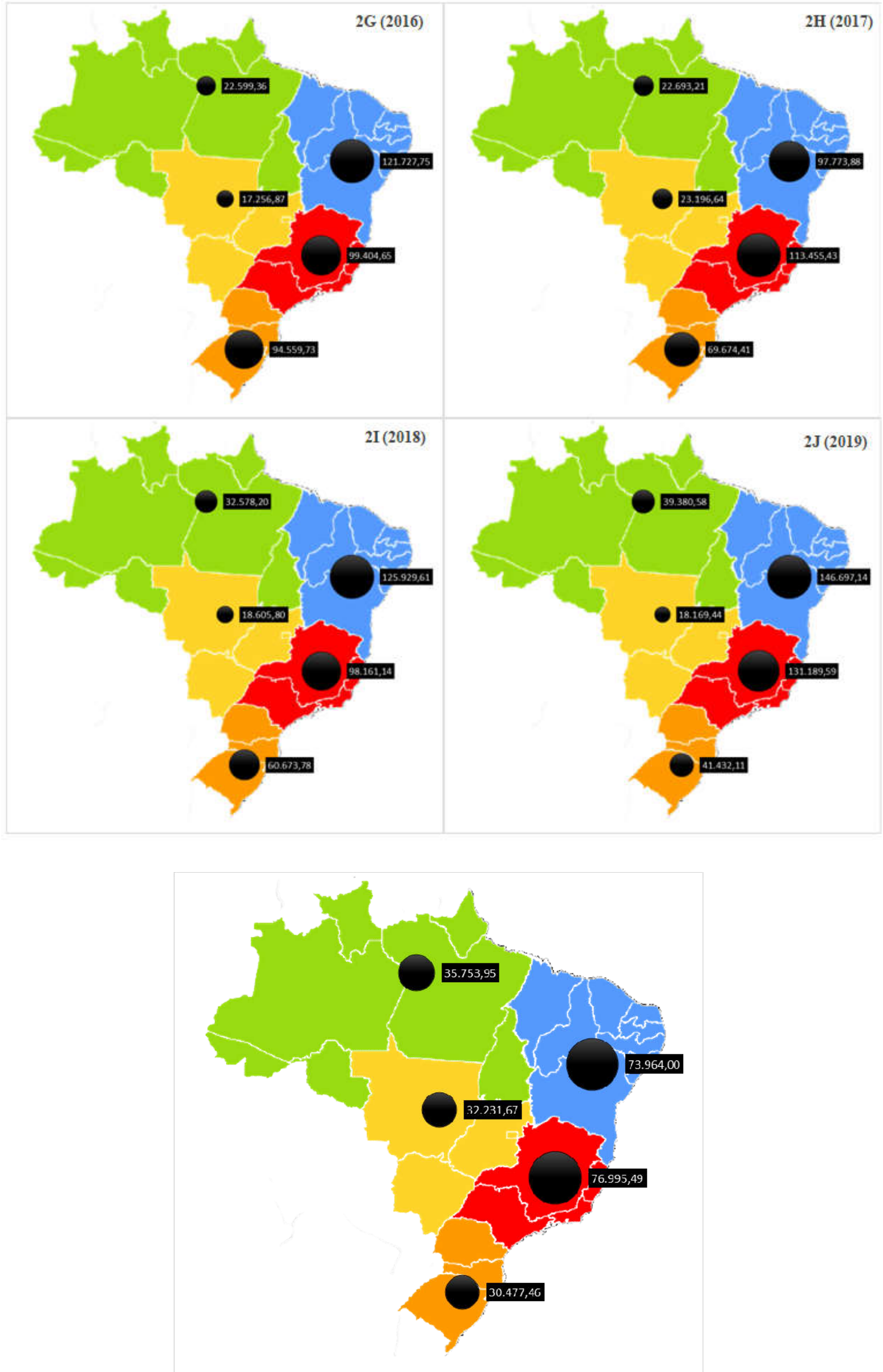

Figura 2. Infográfico do número de internações por anemia ferropriva de acordo as cinco regiões do Brasil, considerando crianças menores de 1 ano, de 1 a 4 anos e de 5 a 9 anos. Figura 2A - ano de 2010; Figura 2B - ano de 2011; Figura 2C - ano de 2012; Figura 2D - ano de 2013; Figura 2E - ano de 2014; Figura 2F - ano de 2015; Figura 2G - ano de 2016; Figura 2H - ano de 2017; Figura 2I - ano de 2018; Figura 2J - ano de 2019; Figura 2K - ano de 2020. Fonte:Bianca Santos Pedrosa (2021). 


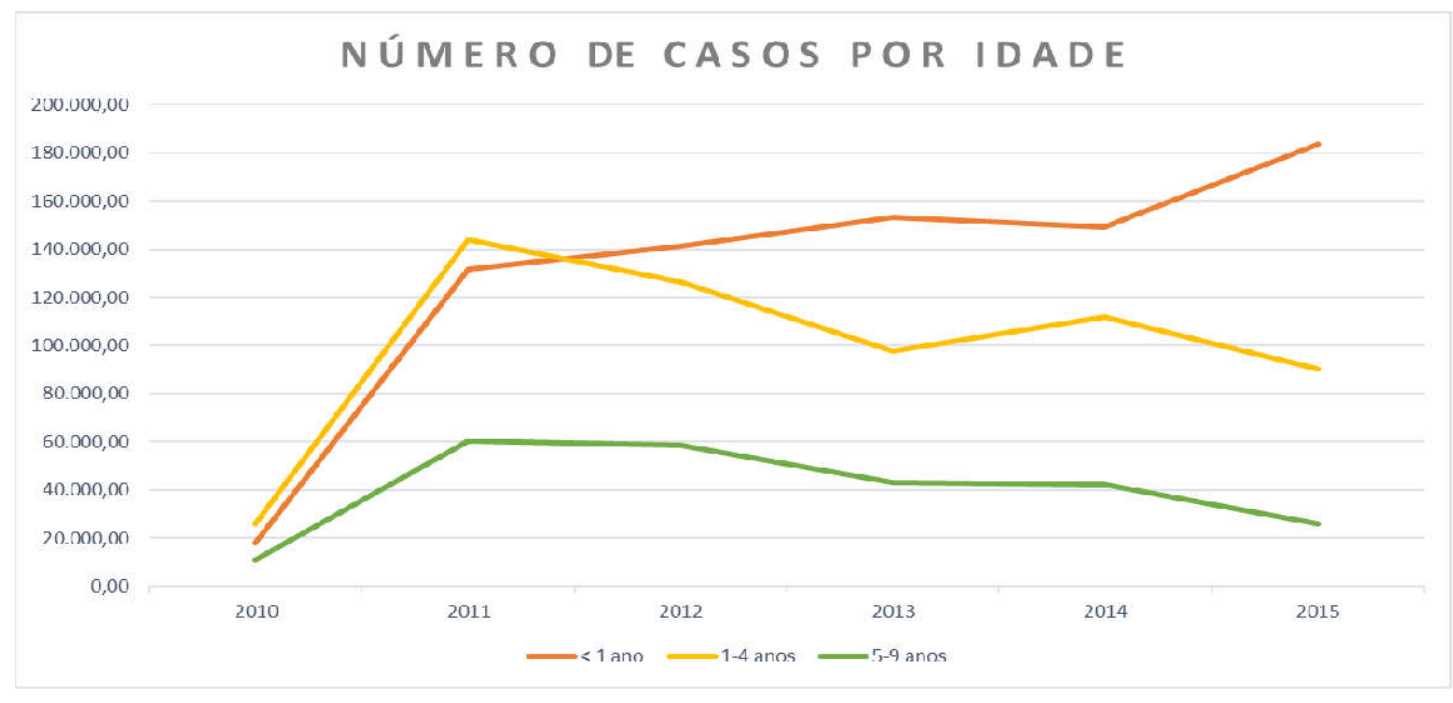

Figura 3. Demonstração gráfica do número de internações por anemia ferropriva de acordo a faixa etária, considerando crianças menores de 1 ano, de 1 a 4 anos e de 5 a 9 anos. Fonte:Bianca Santos Pedrosa (2021)

Os anos de 2010 e 2020, por sua vez, apresentaram o menor número de internações. No que diz respeito ao ano de 2010, supõe-se que os baixos valores se relacionaram com a divulgação de Ações de Educação Alimentar e Nutricional (EAN), conforme o Decreto $\mathrm{N}^{\mathrm{o}}$ 7.272, lançado nesse mesmo ano, referentes a prevenção da anemia ferropriva, estimulado o aleitamento materno exclusivo e prolongado e à alimentação adequada, rica em fontes de ferro com alta biodisponibilidade. Já o ano de 2020 apresentou uma peculiaridade que pode estar intimamente relacionada com a subnotificação dos casos de anemia ferropriva nas crianças - a pandemia pela COVID19, uma doença infectocontagiosa causada pelo novo coronavírus (SARS-CoV-2). Esse cenário trouxe para a população a necessidade do isolamento social, afetando, por vezes, a saúde mental desses indivíduos; estudos demonstram que, durante as epidemias, o número de pessoas cuja saúde mental é afetada tende a ser maior que o número de pessoas afetadas pela infecção (ORNELL, 2020). Essa limitação na exposição social, o que inclui a ida aos sistemas hospitalares e ambulatoriais, gerada pelo medo de contrair a COVID19 pôde, supostamente, ter levado os pacientes a não procurarem os serviços de saúde, gerando assim uma redução no número de casos de anemia ferropriva pela impossibilidade de realizar seu diagnóstico.

Em relação a faixa etária, foi visto que os maiores números de internações por anemia ferropriva envolviam crianças menores de 1 ano. Os estudos nos quais as crianças são analisadas por grupos etários são unânimes em demonstrar uma prevalência bem mais acentuada em crianças de 6-24 meses, referindo que elas apresentam uma prevalência de anemia significativamente maior em relação às crianças de 24-59 meses, da ordem de duas vezes mais (OSÓRIO, et $a l, 2001)$. Tal fato acontece porque esse período se caracteriza como de risco para a anemia, visto que o objetivo principal da alimentação, especialmente durante o primeiro ano de vida, é a aquisição de nutrientes para o crescimento ideal. Logo, fatores que interfiram nesse processo, como um curto período de aleitamento materno, que muitas vezes não se dá de maneira exclusiva, a baixa ingestão de alimentos ricos em ferro, o crescimento acelerado, além da substituição do leite materno por leite de vaca - que pode causar uma proctocolite subclínica gerada pela intolerância às proteínas do leite de vaca, frequentemente levam a um desequilíbrio no metabolismo do ferro, resultando na anemia ferropriva. Outro fator importante relacionado ao quadro é a amamentação sem início de suplementação adequada de sulfato ferroso aos seis meses de vida, como recomenda o Ministério da Saúde no Programa Nacional de Suplementação de Ferro - PNSF, e/ou uso de fórmulas com fortificação insuficiente de ferro (LIACOURAS, et al, 2019). As crianças na faixa etária de 5 a 9 anos tiveram os menores números de internação para anemia ferropriva. Isso acontece porque, embora os requerimentos de ferro decresçam nas idades mais elevadas, o aumento e a diversidade do consumo de alimentos devidos ao crescimento e ao desenvolvimento permitem atingir mais facilmente a adequação do ferro. Para as crianças menores, a dieta monótona, pobre em alimentos ricos em ferro e vitamina $\mathrm{C}$, faz com que seja mais difícil atingir o ponto de corte da anemia estabelecido para os menores de cinco anos como um todo (OSÓRIO, et al, 2001).

\section{CONCLUSÃO}

Por meio desta pesquisa descritiva quantitativa baseada em dados da plataforma DATASUS, foi possível concluir que a prevalência de anemia ferropriva na infância continua alta no Brasil, sendo considerada um grave problema de saúde pública. Identificou-se que a região mais acometida pela doença no período considerado é a região Nordeste, com 38,5\% (1.300.146,29 internações) do número total de internações registradas, fato esse que ocorre, provavelmente, pela presença de vários fatores de risco para anemia nessa região. Já a região Centro-Oeste apresentou-se com o menor número de internações, por possuir as menores densidades demográficas do Brasil (8,7 habitantes por quilômetro quadrado), e, portanto, um menor número de indivíduos doentes; fatores alimentares também estão envolvidos, visto que a economia do Centro-Oeste é baseada no setor primário, supondo então que as crianças da região têm mais acesso a carnes, uma fonte alimentar heme que possui uma alta biodisponibilidade de ferro, prevenindo então a anemia ferropriva.

Dentre o período estudado, o ano de 2015 apresentou o maior número de internaçõesinfantil por anemia ferropriva, sendo uma hipótese para explicar tal fato a baixa adesão profilática do sulfato ferroso e a administração inadequada da estratégia NutriSUS. Os anos de 2010 e 2020, por sua vez, apresentaram o menor número de internações devido a, respectivamente, divulgação de Ações de Educação Alimentar e Nutricional (EAN), conforme o Decreto $\mathrm{N}^{\mathbf{0}} 7.272$, lançado nesse mesmo ano, referentes a prevenção da anemia ferropriva; e o medo coletivo provocado pela pandemia da COVID19, fazendo com que a população não procurasse os serviços de saúde, o que gerou a subnotificação dos casos.Foi visto também que os maiores números de internações envolviam crianças menores de 1 ano - porque esse período se caracteriza como de risco para a anemia, enquanto as crianças na faixa etária de 5 a 9 anos tiveram os menores números, poiso requerimento de ferro decresce nas idades mais elevadas e o aumento e a diversidade do consumo de alimentos devidos ao crescimento e ao desenvolvimento permitem atingir mais facilmente a adequação do ferro. Conclui-se então que, como a população pediátrica apresenta peculiaridades clínicas e epidemiológicas e que o período da infância é essencial para o desenvolvimento de adultos hígidos e longevos, conhecer a 
prevalência da anemia ferropriva em crianças no Brasil, e suas flutuações frente à implementação de políticas públicas para combatêla, é essencial para um melhor planejamento das ações em saúde, contribuindo para uma assistência mais eficiente e de menor custo.

\section{REFERÊNCIAS}

Agência Nacional DE Vigilância Sanitária. 2017. Resolução RDC N ${ }^{\circ}$ 150 , de 13 deabril de. Dispõe sobre o enriquecimento das farinhasde trigo de milho com ferro e ácido fólico. Brasília, 2017.

Albuquerque, et al. 2017. Desigualdades regionais na saúde: mudanças observadas no Brasil de 2000 a 2016. Scielo, abril.

Benedict, SL. et al. Cerebral Sinovenous Thrombosis in Children: Another Reason to Treat Iron Deficiency Anemia. PubMed, julho 2004.

Brasil. Decreto $\mathrm{n}^{\mathrm{0}} 7.272$, de 25 de agosto de 2010. Regulamenta a Lei no 11.346 , de 15 de setembro de 2006, que cria o Sistema Nacional de Segurança Alimentar e Nutricional - SISAN. Brasília, 2010.

Brasil. Ministério da Saúde. 2015. NutriSUS: caderno de orientações: estratégia de fortificação da alimentação infantil com micronutrientes (vitaminas e minerais) em pó, 2015. Disponível em http://bvsms.saude.gov.br/bvs/publicacoes/nutrisus_estrategia fortificacao alimentacao infantil.pdf. Acesso em 21 de maio de 2020.

Brasil. Ministério da Saúde. 2013. Programa Nacional de Suplementação de Ferro: Manual de condutas gerais. Disponível emhttp://bvsms.saude.gov.br/bvs/publicacoes/manual_suplementa cao ferro condutas gerais.pdf. Acesso em 22 de maio de 2020.

Collard, Keith J. Iron Homeostasis in the Neonate. PubMed, abril 2009.

Farias, et al., 2016. The strategy of fortification of infant feeding with micronutrients powder- NUTRISUS. Revista Estado, Meio Ambiente e Desenvolvimento. Disponível em https://congressods .com.br/quinto/anais/gt_10/ESTRATEGIA\%20DE\%20FORTIFI CACAO\%20DA\%20ALIMENTACAO\%20INFANTIL.pdf. Acesso em 28 de mar. 2021.

Gil, Costa, A. 2002. Como Elaborar Projetos de Pesquisa. 4. ed. São Paulo: Atlas.

http://www.ufrgs.br/ufrgs/noticias/arquivos/pandemia-de-medo-ecovid-19-impacto-na-saude-mental-e-possiveis-estrategias. Aceso em: 28 de mar. 2021.
Hill ID, LI Buk, Hopping AG. 2020. Epidemiology, pathogenesis, and clinical manifestations of celiac disease in children. UpToDate, janeiro.

Ibge - 2021. Instituto Brasileiro de Geografia e Estatística. Brasil, Cidades e Estados. Disponível em https://www.ibge.gov.br/ cidades-e-estados.html. Acesso em 28 de mar.

Jordão RE; Bernardi JLD, Barros Filho AA. 2009. Prevalência de anemia ferropriva no Brasil: uma revisão sistemática. Rev paul pediatr. 27(1):90-98

Kassebaum NJ. et al., 2014. A systematic analysis of global anemia burden from 1990 to 2010. PubMed, janeiro.

Kroth D.C., Geremia F., Geremia D.S., Rede assistencial de saúde na região sul do Brasil: evoluçãodos fatores disponíveis no período de 2015 a 2020. Observatório Socioecônomico da COVID-19, Universidade Federal de Santa Maria, 2020. Disponível em https://www.ufsm.br/app/uploads/sites/820/2020/09/Textos-paraDiscussao-16-Rede-Assistencial-de-Saude-na-Regiao-Sul.pdf. Acesso em: 28 de mar. 2021.

Liacouras, C. et al. Food protein-induced allergic proctocolitis of infancy. UpToDate, agosto 2019.

Lobera, Ignacio. 2014. Iron defi ciency andcognitive functions. PubMed, novembro.

Oecd, Health at a Glance 2019: OECD Indicators, OECD Publishing, Paris, 2019. Disponível em https://doi.org/10.1787/4dd50c09-en. Acesso em: 28 de mar.

Ornell, et al., 2020. "Pandemic fear" and COVID-19: mental health burden and strategies. Revista debates in psychiatry - Ahead of print. Disponível em

Osório, M. 2001. Prevalence of anemia in children 6-59 months old in the state of Pernambuco, BrazilPubMed, agosto.

Osório, Mônica. 2002. Fatores determinantes da anemia em crianças: Determinant factors of anemia in children. Jornal de Pediatria, ano, v. 78, n. 269, ed. 4, p. 269-278, 15 abr. 2002. Disponível em: https://www.nescon. medicina.ufmg.br/biblioteca/imagem/ 1561.pdf. Acesso em: 28 demar. 2021.

Pazirandeh, S. et al. Overview of dietary trace elements. UpToDate, março 2020.

Powers, JM. et al. 2020. Iron deficiency in infants and children $<12$ years: Screening, prevention, clinical manifestations, and diagnosis. UpToDate, maio.

Thibault, H. et al. 1993. The immune response in young children with iron deficiency: effect of iron supplementation on cell-mediated immunity. Eur J Pediatr., 152: 120. 